\title{
MATERNAL NEAR MISS- A REVIEW FROM TERTIARY CARE HOSPITAL
}

\author{
Preeti Omprakash Chandak1, Kshama Vivek Kedar²
}

${ }^{1}$ Assistant Professor, Department of Obstetrics and Gynaecology, IGGMC, Nagpur.

${ }^{2}$ Associate Professor, Department of Obstetrics and Gynaecology, IGGMC, Nagpur.

ABSTRACT

\section{BACKGROUND}

Maternal mortality is one of the important indicators used for the measurement of maternal health. Although, maternal mortality ratio remains high, maternal deaths in absolute numbers are rare in a community. To overcome this challenge, maternal near miss has been suggested as a compliment to maternal death and it will help in identifying gaps in health service provision.

Objectives- The objectives of this study were to determine the frequency of maternal near miss cases and to analyse the nature of near miss events.

\section{MATERIALS AND METHODS}

The present cross-sectional observational type of study was done in 2 years' duration in the Department of Obstetrics and Gynaecology, Government Medical College and Hospital, Nagpur. Out of total deliveries, women with severe complications of pregnancy and maternal near miss cases are identified using WHO near miss criteria were included in the study.

\section{RESULTS}

Total 13186 deliveries were conducted during the study period. Out of these 2437 women were identified with severe maternal complications, and out of this 137 were identified as maternal near miss cases. The prevalence of maternal near miss was 1.03. In this study, hypertensive disorders of pregnancy $(0.56)$ followed by haemorrhagic disorders of pregnancy (0.24) was the leading cause of near miss events.

\section{CONCLUSION}

Maternal near miss review serves as a complementary method for auditing the quality of maternal health. The ultimate purpose of the near miss approach is to improve clinical practice and reduce preventable morbidity and mortality through the use of best evidence based practices and emphasis on proper antenatal care.

\section{KEYWORDS}

Maternal Near Miss, Hypertensive Disorders of Pregnancy, Maternal Mortality, Maternal Morbidity.

HOW TO CITE THIS ARTICLE: Chandak PO, Kedar KV. Maternal near miss- a review from tertiary care hospital. J. Evolution Med. Dent. Sci. 2017;6(47):3633-3637, DOI: 10.14260/Jemds/2017/783

\section{BACKGROUND}

Maternal mortality is one of the important indicators used for the measurement of maternal health. Although maternal mortality ratio remains high, maternal deaths in absolute numbers are rare in a community. To overcome this challenge, maternal near miss has been suggested as a compliment to maternal death. ${ }^{1}$ It is defined as pregnant or recently delivered woman who survived a complication during pregnancy, childbirth or 42 days after termination of pregnancy.2,3 Most of the causes of maternal and perinatal mortality are avoidable by providing proper antenatal, intrapartum and postpartum services. The emergency admissions to tertiary health care centre contain large number of patients referred from rural areas. The condition of patient on admission to such referral hospitals and institutions reflects the quality of health services in that particular area, availability of transport facility and efficiency

Financial or Other, Competing Interest: None.

Submission 05-05-2017, Peer Review 30-05-2017,

Acceptance 05-06-2017, Published 12-06-2017.

Corresponding Author:

Dr. Preeti Omprakash Chandak,

Assistant Professor,

Department of Obstetrics and Gynaecology,

IGGMC, Nagpur.

E-mail: 700arpit@gmail.com

DOI: $10.14260 /$ jemds/2017/783

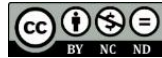

on the part of medical personnel in screening high risk patients who require referral to better equipped and specialised institution. Hence, we must make utmost effort to utilise the existing resources for the benefit of our rural population.

The concept of conducting a Maternal Near-Miss (MNM) review has gained importance as an additional strategy to help identify gaps in health service provision. ${ }^{4}$ Near miss audit has been considered a less threatening approach than maternal death audit, and can be used to identify what needs to be done to improve the quality of maternal health care. ${ }^{5}$ Near miss cases generally occur more frequently than maternal deaths and therefore a more reliable quantitative analysis can be carried out, which can provide a more comprehensive profile of health system functioning.6,7 A substantial proportion of women with one or more lifethreatening conditions are those who have severe pregnancy related complications or receive critical interventions. It is a useful tool for the assessment of quality of maternal health care in the health system, which initiated this study. The maternal near miss approach was primarily developed for use in individual health care facilities.

\section{Aims and Objectives}

1. To determine the frequency of maternal near miss cases attending tertiary care centre.

2. To analyse the nature of near miss events. 


\section{MATERIALS AND METHODS}

This study was carried out in the Department of Obstetrics and Gynaecology, Govt. Medical College, Nagpur, which is a tertiary care institute after taking approval from Institutional Ethical Committee.

\section{Study Period}

The present study was done in 2 years duration from November 2013 to October 2015.

\section{Study Design}

Study design is a hospital-based cross-sectional study.

\section{Inclusion Criteria}

All pregnant women with severe maternal complications with near miss criteria defined by WHO.

\section{Exclusion Criteria}

1. High risk pregnant women who do not fit under WHO near miss criteria.

2. Normal pregnant women.

3. Non-pregnant women.

All admitted high risk cases were identified in the hospital. Out of total deliveries conducted in a tertiary care institute during study period, women with severe complications of pregnancy are identified. The cases of Antepartum Haemorrhage (includes both abruptio placentae and placenta previa) and severe anaemia without haemorrhage are included in this study, as majority of these cases had complications which can be included in near miss criteria.

Out of total deliveries conducted in our tertiary care institute during study period, women with severe complications of pregnancy are identified. From cases with severe complications of pregnancy, maternal near miss cases are identified using WHO near miss criteria. WHO criteria included a set of clinical, laboratory and management based criteria.

\section{These Severe Maternal Complications Include}

- Severe postpartum haemorrhage.

- Severe pre-eclampsia.

- Eclampsia.

- Sepsis or severe systemic infection.

- Ruptured uterus.

- Severe complications of abortion.

- WHO near-miss criteria (Life-threatening conditions).

- Cardiovascular Dysfunction- Shock, cardiac arrest (absence of pulse/heart beat and loss of consciousness), use of continuous vasoactive drugs, cardiopulmonary resuscitation, severe hypoperfusion (lactate $>5 \mathrm{mmol} / \mathrm{L}$ or $>45 \mathrm{mg} / \mathrm{dL})$, severe acidosis $(\mathrm{pH}<7.1)$.

- Respiratory Dysfunction- Acute cyanosis, gasping, severe tachypnoea (respiratory rate $>40$ breaths per minute), severe bradypnoea (respiratory rate $<6$ breaths per minute), intubation and ventilation not related to anaesthesia, severe hypoxaemia $\mathrm{CO}_{2}$ saturation $<90 \%$ for $\geq 60$ minutes or $\mathrm{PAO}_{2} / \mathrm{FiO}_{2}<200$ ).

- Renal Dysfunction- Oliguria non-responsive to fluids or diuretics, dialysis for acute renal failure, severe acute azotaemia (creatinine $\geq 300 \mu \mathrm{mol} / \mathrm{mL}$ or $\geq 3.5 \mathrm{mg} / \mathrm{dL}$ ).

- Coagulation/Haematological Dysfunction- Failure to form clots, massive transfusion of blood or red cells $(\geq 5$ units), severe acute thrombocytopaenia $<50000$ platelets $/ \mathrm{mL}$ ).

- Hepatic Dysfunction- Jaundice in the presence of preeclampsia, severe acute hyperbilirubinaemia (bilirubin > $100 \mu \mathrm{mol} / \mathrm{L}$ or $>6.0 \mathrm{mg} / \mathrm{dL}$ ).

- Neurological Dysfunction- Prolonged unconsciousness (lasting $\geq 12$ hours)/coma (including metabolic coma), stroke, uncontrollable fits/status epilepticus, total paralysis.

- Uterine Dysfunction- Uterine haemorrhage or infection leading to hysterectomy.

\section{Statistical Analysis}

- Continuous variables (Age and Hospital stay in days) were presented as Mean \pm SD. Categorical variables were expressed in actual numbers (frequency) and percentages. Statistical software STATA version 13.0 was used for data analysis.

\section{RESULTS}

Total 137 women were identified as near miss, 72 were booked, while 65 were unbooked women.

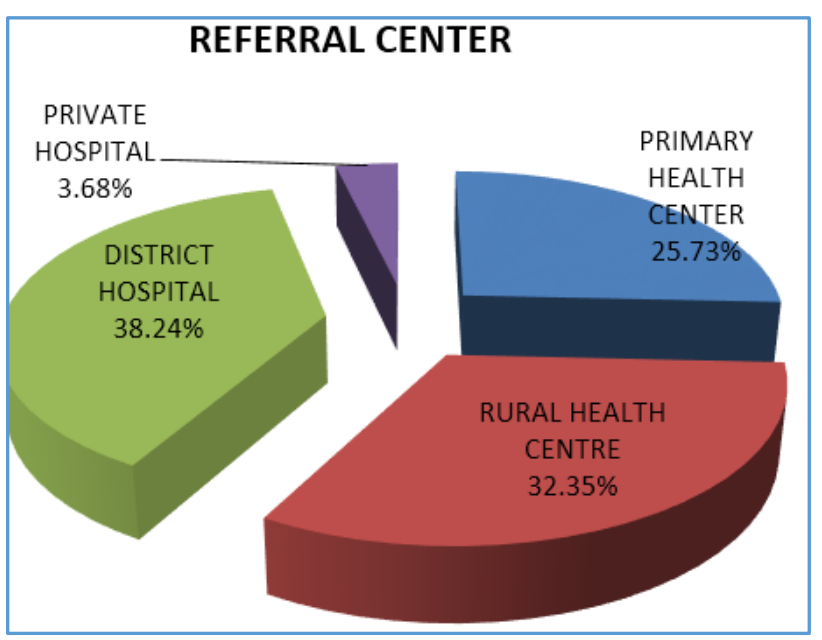

Table 1. Booking Status at Referral Centre

Of these 137 cases, 72 cases (52.5\%) were booked at referral centre and 65 cases (47.5\%) were totally unbooked. Out of 72 booked cases, only 1 case was booked at our tertiary care hospital. Medical assistance was not provided during transport in $93.38 \%$ of patients. Ambulance service was provided in only $21.32 \%$ of patients during transport from referral centre.

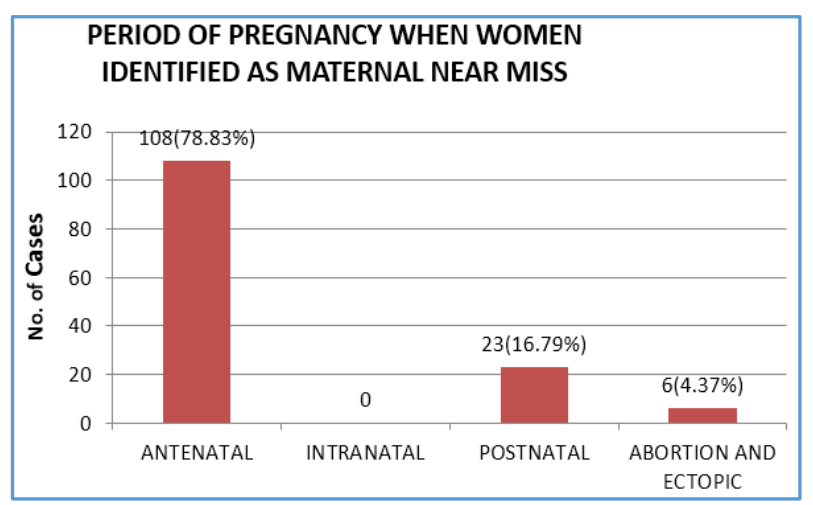

Table 2. Period of Pregnancy when Women Identified as Maternal Near Miss 
Out of total 137 cases, 108 cases were admitted during antenatal period, 23 cases were admitted during postnatal period.

\begin{tabular}{|c|c|c|c|c|}
\hline $\begin{array}{c}\text { Type of } \\
\text { Complication }\end{array}$ & $\begin{array}{l}\text { Total } \\
\text { Cases }\end{array}$ & $\begin{array}{l}\text { Near } \\
\text { Miss } \\
\text { Cases }\end{array}$ & Percentage & Prevalence \\
\hline $\begin{array}{l}\text { Severe Pre- } \\
\text { eclampsia }\end{array}$ & 837 & 30 & 3.58 & \multirow[t]{2}{*}{0.56} \\
\hline Eclampsia & 943 & 48 & 5.09 & \\
\hline $\mathrm{APH}$ & 191 & 19 & 9.95 & \multirow{2}{*}{0.24} \\
\hline $\mathrm{PPH}$ & 177 & 4 & 2.26 & \\
\hline Rupture Uterus & 16 & 6 & 37.5 & 0.04 \\
\hline Sepsis & 15 & 2 & 13.33 & 0.01 \\
\hline $\begin{array}{c}\text { Severe Anaemia } \\
\text { without } \\
\text { Haemorrhage }\end{array}$ & 167 & 21 & 12.57 & 0.15 \\
\hline $\begin{array}{c}\text { Complications of } \\
\text { Abortion }\end{array}$ & 57 & - & - & \multirow{2}{*}{$\begin{array}{l}0.00 \\
0.03\end{array}$} \\
\hline $\begin{array}{c}\text { Complications of } \\
\text { Ectopic }\end{array}$ & 34 & 5 & 14.7 & \\
\hline Other & 2 & 2 & 1 & 0.01 \\
\hline
\end{tabular}

This table shows description of 137 near miss cases. Other cases include 2 cases of post LSCS muscle haematoma that required relaparotomy.

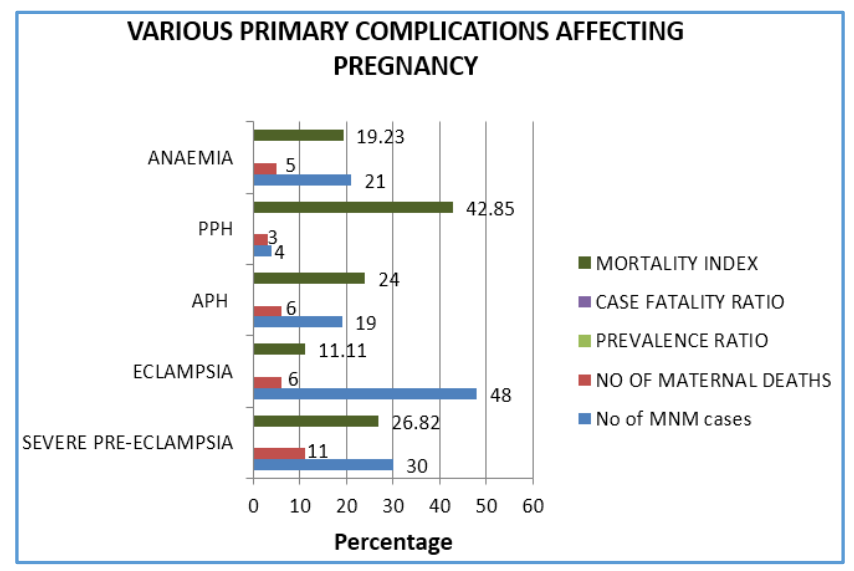

Table 4

This table shows the percentage of near miss cases in relation to specific complications in pregnancy. Case fatality ratio for severe preeclampsia is 0.01 , for eclampsia 0.006 , for APH 0.03, for PPH 0.01 and for severe anaemia it is 0.02 .

\begin{tabular}{|c|c|}
\hline Organ Dysfunction & Number of Near Miss Cases \\
\hline CVS & 59 \\
\hline RS & 15 \\
\hline Renal & 30 \\
\hline Coagulation & 37 \\
\hline Hepatic & 41 \\
\hline CNS & 6 \\
\hline \multicolumn{2}{|c|}{ Table 5. Frequencies of Organ System } \\
Dysfunction in Near Miss Cases
\end{tabular}

This table lists near miss cases as shown by system involvement. CVS and hepatic system involvement was more.

\begin{tabular}{|c|c|c|}
\hline Treatment & Cases & Percentage \\
\hline $\begin{array}{c}\text { Transfusion of } \geq 5 \text { Units of Red Blood } \\
\text { Cells }\end{array}$ & 47 & 34.30 \\
\hline $\begin{array}{l}\text { Uterine Haemorrhage or Infection } \\
\text { Leading to Hysterectomy }\end{array}$ & 4 & 2.91 \\
\hline Continuous Vasoactive Drug Support & 21 & 15.32 \\
\hline $\begin{array}{c}\text { Mechanical Intubation and } \\
\text { Ventilation for } \geq 60 \text { Minutes and } \\
\text { Unrelated to Anaesthesia }\end{array}$ & 10 & 7.29 \\
\hline Dialysis for Acute Renal Failure & 0 & - \\
\hline Cardiopulmonary Resuscitation & 2 & 1.45 \\
\hline Exploratory Laparotomy & 13 & 9.5 \\
\hline Balloon Tamponade & 2 & 1.5 \\
\hline Internal Iliac Artery Ligation & 0 & - \\
\hline $\begin{array}{l}\text { Removal of Retained Products } \\
\text { (Manual Removal of Placenta) }\end{array}$ & 3 & 2.2 \\
\hline Uterine Artery Embolisation & 0 & - \\
\hline
\end{tabular}

This table shows intensive care unit management and surgical management done in near miss cases. Maximum required more than 5 blood transfusions and continuous vasoactive drug support.

\begin{tabular}{|c|c|}
\hline & Total \\
\hline Deliveries (n) & 13186 \\
\hline Live Births (n) & 12757 \\
\hline Cases Near-Miss (n) & 137 \\
\hline Maternal Mortality & 31 \\
\hline On Arrival [n (\%)] & 83 (60.58\%) \\
\hline During Hospitalisation & 54 \\
\hline $\begin{array}{c}\text { Near Miss Cases per 1000 Live Births } \\
\text { (Maternal Near Miss Ratio) }\end{array}$ & 10.73 \\
\hline \multicolumn{2}{|c|}{ Table 7. Maternal Outcome } \\
\hline \multicolumn{2}{|c|}{} \\
\hline
\end{tabular}

This table shows frequency and characteristics of near miss cases. Eighty three percent of the cases were critical on arrival to tertiary care hospital. Fifty four percent cases were critical during hospitalisation.

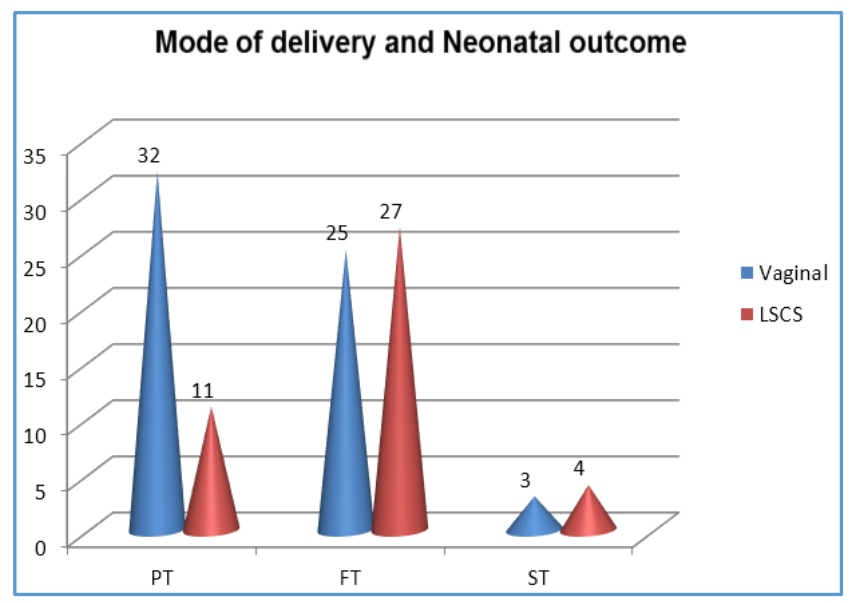

Table 8. Mode of Delivery and Neonatal Outcome

Numbers of preterm vaginal deliveries were more (32) as compared to Caesarean section (11), while full-term deliveries were nearly same. 


\section{DISCUSSION}

During the study period, there were a total of 13186 deliveries conducted at our tertiary care institute. Out of these we identified 2437 patients with severe maternal complications. Total no. of maternal near miss cases identified during study period were 137. Out of these pregnancy complications, in 2437 cases mortality occurred in 31 cases. Majority of women were unbooked (65) and those who were referred (136) was without any medical assistance and ambulance services during transport from referral centre. Majority of the women were primigravida (51\%). The prevalence of maternal near miss was 1.03. This was comparable with study done by Anju Taly et al and C Purandare et al.

\begin{tabular}{|c|c|}
\hline Studies & $\begin{array}{c}\text { Prevalence of } \\
\text { Maternal Near Miss }\end{array}$ \\
\hline Anju Taly et $\mathrm{al}^{8}(2001)$ & 1.10 \\
\hline Shrestha NS et $\mathrm{al}^{9}(2008-2009)$ & 2.3 \\
\hline Ellen JT Nelissen et $\mathrm{al}^{10}(2009-2011)$ & 2.28 \\
\hline Phadouangdeth Luexay et al ${ }^{11}(2010)$ & 0.9 \\
\hline Priyanka Kalra et al $^{12}(2011-2012)$ & 0.4 \\
\hline Roopa PS et al $^{13}(2011-1012)$ & 1.77 \\
\hline C Purandare et al $^{14}(2012-2013)$ & 0.96 \\
\hline Madhavi Nacharaju et al $^{15}(2012-$ & 0.91 \\
\hline 2014$)$ & 1.03 \\
\hline Our Study $^{2}$ & \\
\hline
\end{tabular}

Maternal near miss ratio of our study was 10.73 , which is in comparison with study of Madhavi Nacharaju et al (9.2). Prevalence of hypertensive disorders of pregnancy among total maternal near miss cases is higher in our study (0.56) as compared with other studies as cited above. Prevalence of haemorrhagic disorders of pregnancy among total maternal near miss cases is lower $(0.24)$ than other studies as cited above. Prevalence of sepsis is comparable with other studies. Prevalence of severe anaemia without haemorrhage is 0.15 , which is comparable with study done by Olufemi T Oladapo (0.11). Percentage of near miss cases requiring emergency hysterectomy in this study was $(2.91 \%)$. Number of near miss cases requiring ICU admission for further management in this study (24.1) is comparable to ICU admission rate in study done by C Purandare et al (24.6). In this study $7.29 \%$ of near miss cases required mechanical ventilation. Percentage of near miss cases requiring emergency hysterectomy in this study $(2.91 \%)$ is comparable with study done by Tayebeh Naderi et al ${ }^{16}(2 \%)$.

\section{CONCLUSION}

In this study conducted, majority of near miss cases were unbooked and identified during antenatal period. Majority of patients were primigravida and they were from rural area. There were no accompanying medical personnel with these women. Maximum no. of patients was referred in third trimester of pregnancy. Hypertensive disorders of pregnancy followed by haemorrhagic disorders was the leading cause of near miss events. Cardiovascular system dysfunction was common among near miss cases. Among total cases, 24.1\% required ICU admission.
Maternal near miss is an important indicator of health care system. Health care workers are to be trained to identify the risk factors and refer the cases well before they are potentially life threatening. A better knowledge of the spectrum, characteristics and outcomes of the diseases involving this group of patients is the first step towards achieving prevention and hence reduction of both maternal and neonatal morbidity and mortality. Near miss analysis indicates quality of health care. There is need for application of the maternal near miss concept for assessment of maternal health and quality of maternal care. If the maternal near miss ratio is high, maternal near miss surveillance system should be set up to identify cases of severe maternal morbidity as soon as possible. Timely referral with ambulance services should be provided to these women for better outcome of pregnancy.

\section{REFERENCES}

[1] Chhabra P. Maternal near miss: an indicator for maternal health and maternal care. Indian J Community Med 2014;39(3):132-7.

[2] Say L, Pattinson RC, Gülmezoglu AM, et al. WHO systematic review of maternal morbidity and mortality: the prevalence of severe acute maternal morbidity (near miss). Reproductive Health 2004;1(1):3.

[3] Report on the World Health Organization working group on the classification of maternal deaths and severe maternal morbidities. Geneva, World Health Organization, 2009.

[4] Costello A, Azad K, Barnett S. An alternative strategy to reduce maternal mortality. Lancet 2006;368(9546):1477-9.

[5] Hutchinson C, Lange I, Kanhonou L, et al. Exploring the sustainability of obstetric near miss case reviews: a qualitative study in the South of Benin. Midwifery 2010;26(5):537-43.

[6] Prual A, Bouvier-Colle MH, de Bernis L, et al. Severe maternal morbidity from direct obstetric causes in West Africa: incidence and case fatality rates. Bull World Health Organ 2000;78(5):593-602.

[7] Pattinson RC, Hall M. Near misses: a useful adjunct to maternal death enquiries. Br Med Bull 2003;67:23143.

[8] Taly A, Gupta S, Jain N. Maternal intensive care and "Near-miss" mortality in obstetrics. J Obstet Gynecol Ind 2004;54(5):478-82.

[9] Shrestha NS, Saha R, Karki C. Near miss maternal morbidity and maternal mortality at Kathmandu Medical College Teaching Hospital. Kathmandu University Medical Journal 2010;8(30):222-6.

[10] Nelissen EJ, Mduma E, Ersdal HL, et al. Maternal near miss and mortality in a rural referral hospital in northern Tanzania: a cross-sectional study. BMC Pregnancy and Childbirth 2013;13:141.

[11] Luexay P, Malinee L, Pisake L, et al. Maternal near-miss and mortality in Sayaboury Province, Lao PDR. BMC Public Health 2014;14:945. 
[12] Kalra P, Kachhwaha CP. Obstetric near miss morbidity and maternal mortality in a Tertiary Care Centre in Western Rajasthan. Indian J Public Health 2014;58(3):199-201.

[13] Roopa PS, Verma S, Rai L, et al. "Near Miss" obstetric events and maternal deaths in a tertiary care hospital: an audit. Journal of Pregnancy Article ID 393758, 2013;2013:5.

[14] Purandare C, Bhardwaj A, Malhotra M, et al. Maternal near-miss reviews: lessons from a pilot programme in India. BJOG 2014;121(Suppl 4):105-11.
[15] Nacharaju M, Sudhir SP, Kaul R, et al. Maternal near miss: an experience in rural medical college. JEMDS 2014;3(56):12761-7.

[16] Naderi T, Foroodnia S, Omidi S, et al. Incidence and correlates of maternal near miss in Southeast Iran. International Journal of Reproductive Medicine Article ID 914713, 2015;2015:5. 